\title{
Природные и техногенные факторы формирования фильтрационных потоков подземных вод Северного Синая
}

\author{
(С2021 Я. ШІ. Мохамед ${ }^{1}$, В. А. Бударина ${ }^{2 凶}$, И. И. Косинова ${ }^{2}$, Н. А. Виноград ${ }^{3}$, А. А. Потапов ${ }^{4}$ \\ ${ }^{1}$ Загазигский университет, ул. Эль-Модир, 44519, Загазиг, Шаркия, Египет \\ ${ }^{1}$ Воронежский государственный университет, \\ Университетская пл., 1, 394018, Воронеж, Российская Федерация \\ ${ }^{3}$ Санкт-Петербургский государственный университет, \\ Университетская наб. 7/9, 199034, Санкт-Петербург, Российская Федерация \\ ${ }^{4}$ Горный институт Уральского отделения Российской академии наук, \\ филиал Пермского федерального исследовательского центра УрО РАН, \\ ул. Сибирская, д. 78а, 614007, Нермь, Российская Федерация
}

\begin{abstract}
Аннотация
Bведение: Северная часть Синайского полуострова расположена в зоне аридного климата, регион характеризуется острым недостатком доступной воды удовлетворительного качества. Практически единственным источником пресных вод являются гидрогеологические скважины. Дальнейшее развитие региона, ориентированное на расширение горнодобывающей деятельности, предполагает значительное увеличение потребностей в воде. В этой связи целью настоящей работы стало изучение природных и техногенных факторов фильтрационных потоков подземных вод, используемых и перспективных для хозяйственно-питьевого водоснабжения северной части Синайского полуострова. Методика: Методика проведенных исследований включала создание банка данных по уровенному режиму четвертичных и дочетвертичных водоносных горизонтов региона, который включил наблюдения по 151 скважине. 45 скважин характеризовали гидрогеологическую ситуацию по трем выборкам для четвертичных отложений; в долине Вади Эль-Ариш и в округах Рафах и Шейх Зувид. Дочетвертичные водоносные горизонты оценивались по выборке из 60 скважин. С помощью программы SPSS был проведен статистический анализ динамики уровней воды в гидрогеологических скважинах, на основе которых с использованием ГИС технологий были построены карты гидроизогипс и гидроизопьез для каждого водоносного горизонта, также построена обобщенная гидродинамическая сетка потока для отслеживания движения подземных вод на Северном Синае.

Результаты и обсуждение: Подчеркнуто, что распространение водоносных горизонтов значительной мощности в четвертичных отложениях ограничено только прибрежной равниной, тянущейся вдоль Средиземного моря. Выявлены основные закономерности формирования фильтрационного потока подземных вод северного Синая, которые заключаются в следующем: а) общий поток подземных вод движется в субгоризонтальном направлении - в основном с юга на север, в сторону общего стока в Средиземное море, также частично в западном и восточном - в сторону Суэцкого залива и залива Акаба; б) в среднем гидравлический уклон основного фильтрационного потока подземных вод четвертичного возраста с юга на север составляет около 0.002 ; в) показатели статических уровней подземных вод в четвертичных отложениях в пределах прибрежной равнины колеблются в диапазоне - от +8.10 до -8.40 м, отрицательные значения характерны для участков работы эксплуатационных скважин; г) дочетвертичные водоносные горизонты залегают в диапазоне глубин
\end{abstract}

Контент доступен под лицензией Creative Commons Attribution 4.0 License.

\footnotetext{
๑ Бударина Виктория Александровна, e-mail: budarinav@yandex.ru
} 
от 3.1 до 420 м. Гидравлические уклоны в водоносных горизонтах дочетвертичных отложений подземных вод фиксируются в песчаниках (330-410 м абс.) и составляют 0.003; д) отмечается общая тенденция к повышению минерализации по мере уменьшения абсолютных отметок уровней подземных вод.

Заключение: Выявленные природные и техногенные факторы формирования структуры фильтрационного потока севера Синайского полуострова позволят оптимизировать существующее водоснабжение в направлениях наиболее эффективного использования четвертичного водоносного горизонта в центральной части исследуемой территории; методического обоснования эксплуатация меловых водоносных горизонтов, исключающего повышении минерализации подземных вод. Обобщенная карта структуры фильтрационного потока подземных вод станет основой развития водохозяйственного комплекса в пределах Северного Синая.

Ключевые слова: фильтрационный поток, четвертичные и дочетвертичные водоносные горизонты, гидродинамическая сетка, Северный Синай

Источник финансирования: Статья подготовлена при поддержке: Российского фонда фундаментальных исследований, договор №_20-55-00010 от 30.04.2020 г. и Белорусского республиканского фонда фундаментальных исследований, договор №X20Р-284 от 04.05.2020 г.

Для цุитирования: Мохамед Я. Ш., Бударина В. А., Косинова И. И. Виноград Н. А., Потапов А. А. Природные и техногенные факторы формирования фильтрационных потоков подземных вод Северного Синая // Вестник Воронежского государственного университета. Серия: Геология. 2021. №4. C.71-81. DOI: https://doi.org/10.17308/geology.2021.4/3792

\section{Введение}

Актуальность данной работы связана с тем, что северная часть Синайского полуострова расположена в зоне аридного климата, регион характеризуется острым недостатком доступной воды удовлетворительного качества. Перспективы развития региона в настоящее время связаны с деятельностью горнодобывающего комплекса, что в значительной степени увеличивает потребность в воде. При этом практически единственным источником пресных вод являются гидрогеологические скважины. Работа является частью комплексного гидрогеологического исследования севера Синайского полуострова (Египет). Уровенный режим подземных вод представлен отдельно для водоносных горизонтов четвертичных и дочетвертичных отложений. Составлены карты гидроизогипс и гидроизопьез по каждому водоносному горизонту в пределах Северного Синая, а также выстроена обобщенная сетка потока подземных вод. Гидросфера данного региона в значительной степени зависит от тектонических условий территории [1]. Значимым фактором преобразования гидрогеологических условий района исследований является интенсивная откачка подземных вод в целях хозяйственно-питьевого водоснабжения. Результаты проведенных работ используются административными органами региона для более эффективного планирования и управления ресурсами подземных вод на Северном Синае.

\section{Методика работ}

Для описания структуры фильтрационных потоков подземных вод Северного Синая были изучены результаты всех ранее проведенных исследований в этом районе, связанных с построением карт гидроизогипс и гидроизопьез, определением основных направлений фильтрационных потоков в различных локальных областях, включая исследования, выполненные в послед- ние годы. [2-10]. Была использована информация о гидрогеологических скважинах, содержащаяся в сводном отчете «Исследование ресурсов подземных вод Северного Синая в Арабской Республике Египет» (JICA 1992) [11], а также дополнительно предоставленная Институтом водных исследований (WRRI) Министерства ирригации и водных ресурсов Арабской Республики Египет [12-18]. По результатам проведения полевых работ обновлена информация об уровнях грунтовых вод во всех существующих гидрогеологических скважинах в районе Северного Синая. С помощью программы SPSS был проведен статистический анализ для оценки динамики уровней воды в гидрогеологических скважинах. Результатом систематизации стала соответствующая база данных, в которую вошли материалы по 151 скважине. На основе этих данных с использованием географической информационной системы (ГИС) были построены карты гидроизогипс и гидроизопьез, а затем - обобщенная гидродинамическая сетка потока для отслеживания движения подземных вод на Северном Синае путем построения линий тока, перпендикулярных эквипотенциалам. Кроме того, в ГИС были разработаны 3D-модели четвертичного и дочетвертичного водоносных горизонтов территории, показывающие глубину залегания водоносных горизонтов и их положение в разрезе.

\section{Результаты исследований и их обсуждение}

Четвертичный водоносный горизонт. Водоносный горизонт значительной мощности в четвертичных отложениях распространен только на прибрежной равнине вдоль Средиземного моря, где он тянется вдоль берега полосой шириной от 10 до 15 км от устья Вади Эль-Ариш до Рафаха (рис. 1). Для построения карт гидроизогипс были получены данные о положении статического уровня грунтовых вод (УГВ) в 45 скважинах. Эти данные распределены следующим 


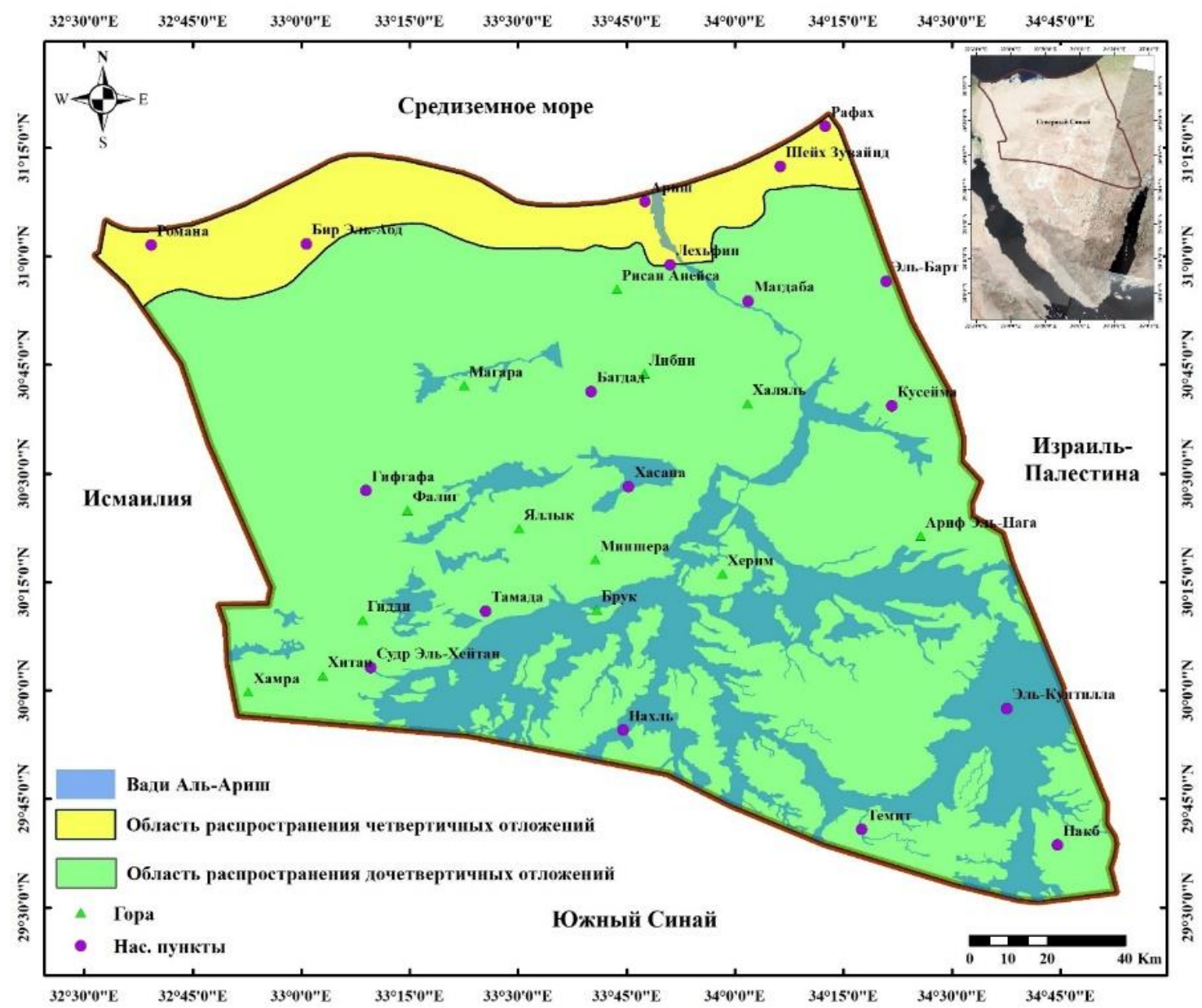

Рис. 1. Зоны распространения четвертичных отложений и выхода на поверхность дочетвертичных отложений территории Северного Синая.

[Fig. 1.Zones of distribution of Quaternary deposits and outcropping of pre-Quaternary deposits of the North Sinai. Translation symbols from the тар: Средиземное море - Mediterranean Sea, Исмаилия - Ismailia, Израиль-Палестина - Israel and Palestine, Южный Синай - South Sinai, Вади Аль-Aриш - Wadi El-Arish, Область распространения четвертичных отложений - Area of Quaternary deposits, Область распространения дочетвертичных отложений - Area of pre-Quaternary deposits, Гора - Mountain, Hac. nyнкты -Cities and localities, Романа - Rummanah, Бир Эль-Aбд - Bir al-Abd, Paфax - Rafah, Apuш - Arish, Шейх Зувайнд - Sheikh Zиweid, Эль-Барт - ElBart, Магдаба - Magdaba, Mazapa - Magara, Лехьфин - Lekhfin, Гифгафa - Gifgafa, Pисан Анейса - Risan Aneisa, Багдад - Baghdad, Либни - Libni, Фалиг - Falig, Ялльк - Yallyk, Тамада - Thamada, Гидди - Gidi, Хамра -Haтra, Хитам - Hitam, Хасана - Hаsana, Миншера - Minshera, Халяль - Halyal, Kусейма - Quseima, Cyдp Эль-Хейтан - Sudr El-Heitan, Apиф Эль-Haza - Arif El-Naga, ЭльКунтилла - El Kuntilla, Гемит - Geтit, Набк-Nabq, Нахль - Nakhl, Брук-Bruq.]

образом: 33 скважины в районе Вади Эль-Ариш (зона А) и 12 скважин в районах Рафах и Шейх Зувид (зона Б) (рис. 1). С помощью программы SPSS был проведен статистический анализ для оценки измеренных уровней воды в гидрогеологических скважинах. Для четвертичных отложений рассматривались различные выборки данных в зависимости от областей отбора: 1) замеры для всех четвертичных отложений («Все»); 2) в долине Вади Эль-Ариш (зона А); и 3) в округах Рафах и Шейх Зувид (зона Б).

Результаты расчета статистических параметров приведены в таблице 1. Как показано в таблице, абсолютные отметки статических уровней подземных вод в четвертичных отложениях в пределах прибрежной равнины колеблются в очень узком диапазоне - от +8.10 до -8.40 м (в зоне А от +3.10 до -8.40 м, в зоне Б
- от +8.10 до +0.90 м). Причем отрицательные значения однозначно связаны с водозаборными скважинами,эксплуатирующими грунтовые воды.

Очевидно, что в районе вади Эль-Ариш_помимо основного направления потока подземных вод в сторону генеральной дрены - Средиземного моря, наблюдаются также локальные изменения данного потока, обусловленные двумя факторами:

1) дренажным влиянием самого вади, в особенности в засушливой части года;

2) дренажным эффектом от эксплуатационных водозаборных скважин (рис. 2).

Максимальные отметки уровня воды закономерно наблюдаются на юге прибрежной равнины, то есть в области питания четвертичных водоносных горизонтов со стороны дочетвертичных отложений, и также 


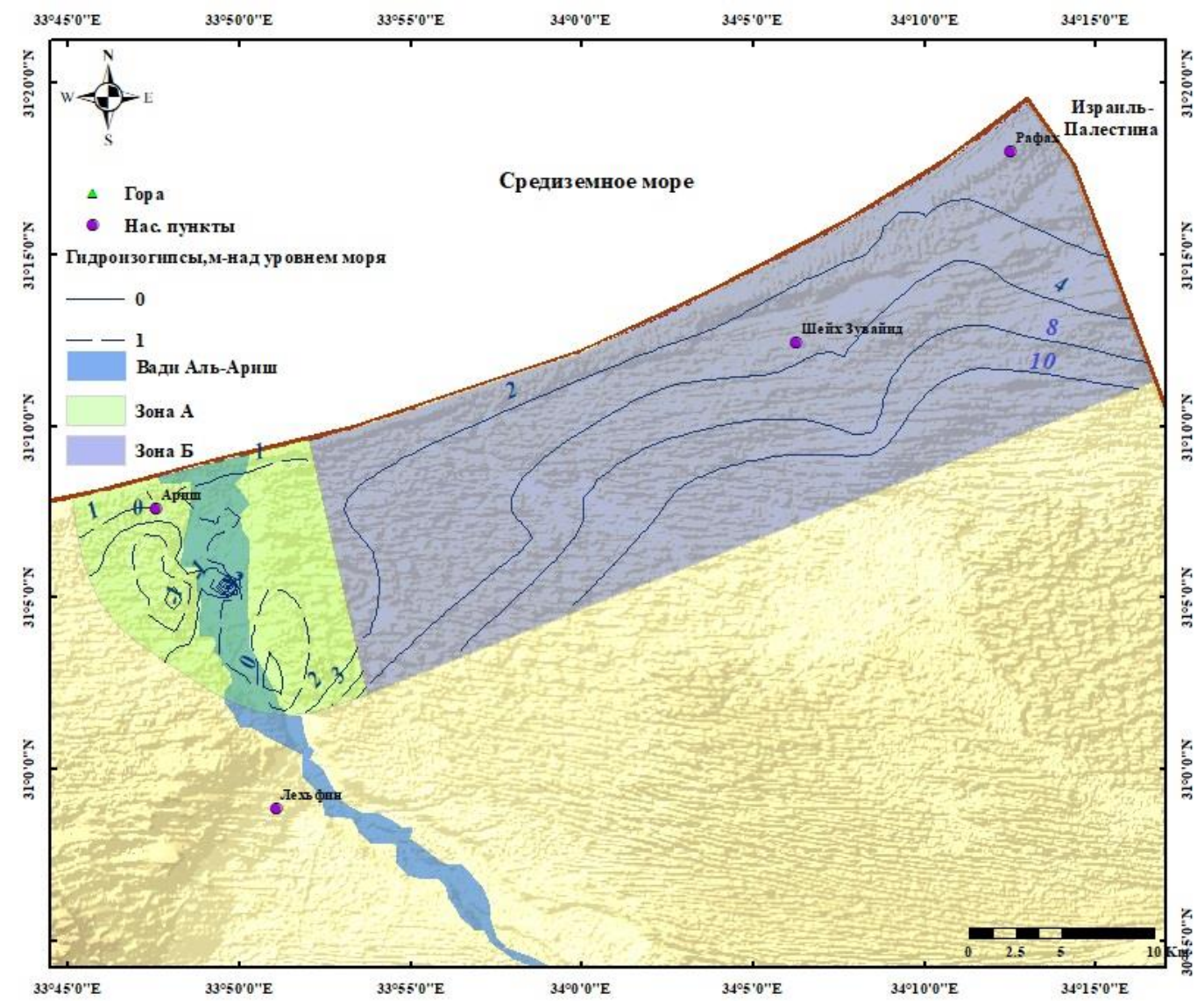

Рис. 2. Карта гидроизогипс водоносного горизонта четвертичных отложений (район вади Эль-Ари).

[Fig. 2. Map of the hydroisohypsum of the aquifer of Quaternary deposits (Wadi El Ari area. Translation symbols from the map: Cpeduземное море - Mediterranean Sea, Гора - Mountain, Hac. пункты - Cities and localities, Израиль-Палестина - Israel and Palestine, Гидроизогипсы - hydroisohypsum, m above sea level, Вади Аль-Aриш - Wadi El-Arish, Зона A-Area A, Зона Б-Area B.]

Табл. 1. Статистические параметры УГВ (м абс. отм.) для водоносного горизонта четвертичных отложений [Table 1. Statistical parameters of the groundwater Level (m abs. elevation) for the aquifer of Quaternary deposits]

\begin{tabular}{|c|c|c|c|}
\hline $\begin{array}{c}\text { Параметр } \\
\text { [Рarameter] }\end{array}$ & $\begin{array}{c}\text { Все } \\
\text { [All] }\end{array}$ & $\begin{array}{c}\text { Зона_А } \\
\text { [Zone_A] }\end{array}$ & $\begin{array}{c}\text { Зона_Б } \\
\text { [Zone_В] }\end{array}$ \\
\hline $\begin{array}{c}\text { Число измерений } \\
\text { [Number of measurements] }\end{array}$ & 45 & 33 & 12 \\
\hline $\begin{array}{c}\text { Среднеe } \\
\text { [The average] }\end{array}$ & 1.05 & 0.30 & 3.10 \\
\hline $\begin{array}{c}\text { Медиана } \\
\text { [Mеdian] }\end{array}$ & 1.20 & 0.90 & 2.60 \\
\hline $\begin{array}{c}\text { Станд. Отклонение } \\
\text { [Standard deviation] }\end{array}$ & 2.50 & 2.10 & 2.20 \\
\hline $\begin{array}{c}\text { Минимум } \\
\text { [Міпітит] }\end{array}$ & -8.40 & -8.40 & 0.90 \\
\hline $\begin{array}{c}\text { Максимум } \\
\text { [Махімит] }\end{array}$ & 8.10 & 3.10 & 8.10 \\
\hline
\end{tabular}

закономерно снижаются в сторону к оси вади, уменьшаясь в целом до 0 м абс. по урезу воды Средиземного моря. Исключениями из этого правила оказываются только точки расположения водозаборных скважин, где отметки уровней подземных вод опускаются ниже 0 м абс. В районах Рафах и Шейх Зувид (зона Б) направление потока подземных вод определяется в основном, как и в зоне А, их движением от южной границы четвертичных водоносных горизонтов на север, к берегу Средиземного моря. Дренажный эффект со стороны мелких вади играет здесь подчиненную роль. И ещё меньшее значение имеют отдельные водозаборные скважины с малыми дебитами откачки.

Не исключено, что снижение уровня воды в водозаборных скважинах может повлиять на качество откачиваемых подземных вод. Для оценки этого эффекта для обеих зон были построены корреляционные зависимости минерализации подземных вод от отметок уровней воды в скважинах (рис. 3).

Отмечено, что для обеих зон А и Б очевидной тенденции к увеличению минерализации при отрицательных или близких к нулю отметках уровня воды в скважинах не наблюдается. И, наоборот, наблюдается некоторая тенденция к росту минерализации при увеличении отметок уровня воды в скважинах при значениях последних больше нуля. Эти закономерности требуют дальнейшего изучения по мере накопления актуального фактического материала. 


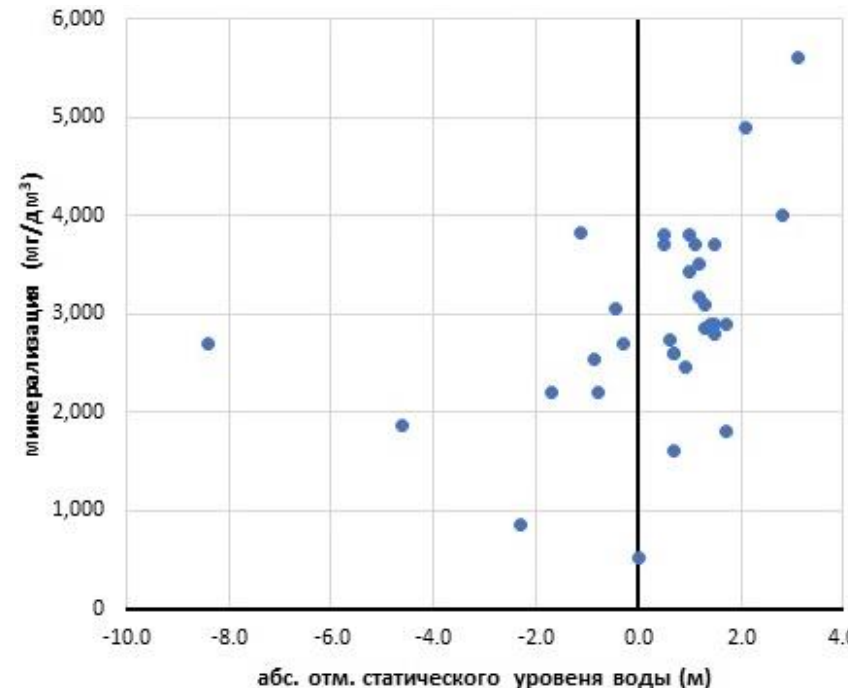

Рис. 3. Зависимость минерализации подземных вод четвертичных отложений $\left(\right.$ мг/дм $\left.{ }^{3}\right)$ от положения статического уровня (м абс.).

[Fig. 3. Dependence of groundwater salinity of Quaternary sediments $\left(\mathrm{mg} / \mathrm{dm}^{3}\right)$ on the position of the static level (m abs.). Translation symbols: Минерализация - Mineralisation $\left(\mathrm{mg} / \mathrm{dm}^{3}\right)$, абс. отм. статического уровня воды - absolute elevation of the static level of water $(m)$.]

Дочетвертичный водоносный горизонт. Морфологически территория Синайского полуострова, состоит из двух основных зон - Центрального плато и складчатых гор Сирийской зоны, которая простирается от Сирии через Ливан и Израиль. Южная часть Синая представляет собой сложную систему складчатых гор, образованных докембрийскими магматическими и метаморфическими породами. Эта область характеризуется самыми высокими абсолютными отметками на Синайском полуострове.

Отслеживание направлений вади позволяет проследить и направление потока подземных вод, соответствующее абсолютным отметкам с юга на север Синая. Вади представляют собой русла временных водотоков, которые заполняются только во время ливневых дождей. Они протягиваются на десятки километров, нередко имеют крутые склоны. Южная часть полуострова представляет собой массивное известняковое плато. Дренажная система в основном формируется на севере Вади-эль-Ариш с многочисленными областями разгрузки, которые образуют зоны сбора и накопления подземных вод и определяют направление их стока. Восточные и западные края расчленены глубокими ущельями, впадающими в залив Акаба и Суэцкий залив. Выявлено, что подземные воды исследуемого водоносного горизонта, расположенного на востоке и западе Синая, движутся в сторону залива Акаба и Суэцкого залива.

В центральной части крутой региональный склон разбит на множество больших холмов, к северу от которых расположен пояс низменностей с высокими песчаными дюнами вдоль побережья Средиземного моря, что определяет направление потока подземных вод с юга на север Синая и его разгрузку в Средиземное море.

Район, в котором находятся дочетвертичные водоносные горизонты, состоит из больших горных блоков, которые относятся к зоне Сирийской дуги - Гебель Магара, Халяль и Еллек. Они расположены вдоль большой оси, направленной с юго-запада на северо-восток. В геологическом отношении они сложены известняками, мергелями и песчаниками, возраст которых варьирует от юры до верхнего мела. Данные породы выступают в качестве вмещающих для водоносных горизонтов в этих районах. Горные районы окружены холмами. Многие из холмов, сложенных третичными и четвертичными делювиальными отложениями, расположены в верхнем течении дренажной системы Вади-эль-Ариш.

Были получены данные о статических уровнях подземных вод по 106 скважинам, вскрывающим дочетвертичные водоносные горизонты. Данные были статистически обработаны, чтобы гарантировать их правильную интерпретацию и значимость корреляционных связей. База данных для обработки включала результаты замеров по 46 скважинам, приуроченным к трещиноватым верхнемеловым известнякам (ВГИ) и 60 скважинам, вскрывающим водоносный горизонт нижне-верхнемеловых нубийских песчаников (ВГП). Расположение гидрогеологических скважин на дочетвертичных водоносных горизонтах, а также мощность и гипсометрическое положение вмещающих пород моделировались в трехмерной модели с использованием ГИС технологий.

На основе программы SPSS был проведен описательный статистический анализ значений статических уровней воды из скважин, вскрывающих различные водоносные горизонты в дочетвертичной зоне.

Для дочетвертичных отложений были рассмотрены различные выборки данных в зависимости от литологии исследуемых водоносных горизонтов:

1) для всех дочетвертичных отложений («Все»);

2) водоносный горизонт трещиноватых верхнемеловых известняков (ВГИ);

3) водоносный горизонт нижне-верхнемеловых нубийских песчаников (ВГП). Результаты расчета статистических параметров приведены в таблице 2 .

Как показано в таблице, в целом, значения статического уровня во всех скважинах имеют приемлемую степень достоверности, поскольку изменчивость относительно среднего значения довольно мала. Близость среднего и медианы указывает на отсутствие «выскакивающих» значений.

Результаты показали, что статические уровни подземных вод дочетвертичных отложений, в отличие от уровней в четвертичных отложениях на прибрежной равнине, колеблются в очень широком диапазоне от 3.1 до 420 м. Таким образом, гидравлические уклоны в ВГ дочетвертичных отложений значительно больше, чем в ВГ четвертичных пород прибрежной равнины вдоль побережья Средиземного моря. 
Табл. 2. Статистический анализ статического уровня дочетвертичных водоносных горизонтов

[Table 2. Statistical analysis of the static level of pre-Quaternary aquifers]

\begin{tabular}{|c|c|c|c|}
\hline \multirow{2}{*}{$\begin{array}{l}\text { Параметр } \\
\text { [Parameter] }\end{array}$} & \multicolumn{3}{|c|}{$\begin{array}{c}\text { A.о. стат.уровня, (м) } \\
\text { [Absolute elevation of the static level, m)] }\end{array}$} \\
\hline & $\begin{array}{l}\text { Bce } \\
{[\text { All] }}\end{array}$ & $\begin{array}{c}\text { ВГИ } \\
\text { [limestone } \\
\text { aquifer] }\end{array}$ & $\begin{array}{c}\text { ВГП } \\
\text { [sandstone } \\
\text { aquifer] }\end{array}$ \\
\hline $\begin{array}{c}\text { Число } \\
\text { измерений } \\
\text { [Number } \\
\text { of measurements] }\end{array}$ & 106 & 46 & 60 \\
\hline $\begin{array}{c}\text { Среднее } \\
\text { [The average] }\end{array}$ & 181,50 & 122,5 & 227 \\
\hline $\begin{array}{l}\text { Медиана } \\
\text { [Median] } \\
\end{array}$ & 180 & 119,50 & 224 \\
\hline $\begin{array}{c}\text { Стандартное } \\
\text { отклонение } \\
\text { [Standard } \\
\text { deviation] }\end{array}$ & 95 & 69,50 & 87,50 \\
\hline $\begin{array}{l}\text { Минимум } \\
\text { [Minimum] }\end{array}$ & 3,10 & 3,10 & 23,56 \\
\hline $\begin{array}{l}\text { Максимум } \\
\text { [Maximum] }\end{array}$ & 420 & 300 & 420 \\
\hline
\end{tabular}

В известняках верхнемелового возраста и суммарно по ВГ дочетвертичных отложений в некоторых областях, например, в окрестностях Гебель Фалиг, Гебель Халяль, Хасана и Рисан Анейса, уровни подземных вод значительно ниже, чем в соседних районах, что, очевидно, связано с интенсивной откачкой из скважин, поскольку здесь подземные воды являются единственным источником водоснабжения. И, наоборот, в окрестностях Гебель Магара и Кусеймы уровень воды поднимается до 200 м абс., что однозначно следует считать повышенным по сравнению с уровнями в соседних районах (рис. 4). Это, по-видимому, связано с расположением этих участков на относительно возвышенной территории, внутри известняковых блоков, гидравлически изолированных от окружающих зон.

В соответствии с общим направлением фильтрационного потока с юга на север, самые высокие уровни подземных вод в песчаниках (330-410 м абс.) наблюдаются в районе Эль-Кунтилла на юго-востоке и в Судер-Эль-Хейтане на юго-западе Северного Синая, а самые низкие уровни порядка 50 м абс. - к северо-востоку от Гебель Халяль. Таким образом, пьезометрическая поверхность в водоносном горизонте, сложенном песчаниками, опускается в направлении с юга на север со средним гидравлическим уклоном порядка 0.003 . При этом, как и в случае с известняками, на некоторых участках, например, в районе Гебель-Херим, уровень подземных вод в песчаниках заметно ниже, чем в соседних районах, возможно, из-за интенсивной откачки. Отмечается некоторая тенденция к повышению минерализации по мере уменьшения абсолютных отметок уровней подземных вод, как в нижнемеловых, так и в верхнемеловых водоносных горизонтах.
Следовательно, не исключено, что в откачивающих скважинах по мере снижения уровней будет наблюдаться ухудшение качества воды, по крайней мере, в сторону увеличения минерализации [19].

\section{Обобщенная структура}

\section{фильтрационного потока Северного Синая}

На рис. 5 показана обобщенная структура фильтрационного потока подземных вод на Северном Синае, составленная по всем значениям уровней в различных водоносных горизонтах.

Обобщенная структура фильтрационного потока обсуждалась авторами ранее в работе [20]. Как было показано, для отдельных водоносных горизонтов (рис. $2,4)$, обобщенный поток подземных вод, перетекающих в субгоризонтальном направлении из одних горизонтов в другие, направлен в основном с юга на север Северного Синая, в сторону генеральной дрены - Средиземного моря, а также частично в западном и восточном направлениях, в сторону залива Акаба и Суэцкому (в том числе и к Суэцкому каналу). В среднем гидравлический уклон основного фильтрационного потока подземных вод с юга на север составляет порядка 0.002. Закономерно, что направление внутренних, более локальных потоков подземных вод связано с наличием повышенных и пониженых участков рельефа и, как следствие, пониженных отметок уровней подземных вод. Иначе говоря, обобщенный поток подземных вод направлен от областей их питания, таких как районы Нахл, Темед и Судер-эль-Хейтан, к областям их разгрузки, к Средиземному морю, Суэцкому заливу и заливу Акаба, а также (в локальном смысле) к долинам основных вади.

1. Выявленные природные и техногенные факторы формирования структуры фильтрационного потока севера Синайского полуострова позволят оптимизировать существующее водоснабжение в следующих направлениях: перспективы дальнейшего использования четвертичного водоносного горизонта северной части Синайского полуострова могут быть связаны с его центральной частью, в пределах которой статические уровни горизонта наиболее стабильны. Определенные риски прогнозируются при расположении гидрогеологических скважин в районах различных вади, являющихся локальными структурами разгрузки фильтрационного потока.

2. Интенсивная эксплуатация меловых водоносных горизонтов приводит к локальным падениям их уровней, что согласно основной гидрогеохимической закономерности, приведет к повышению минерализации подземных вод с последующим ограничением их использования в хозяйственно-питьевых целях. Целесообразным является моделирование взаимодействия эксплуатационных скважин для обоснования размещения последующих водозаборных объектов, прогноз изменения качества подземных вод. 

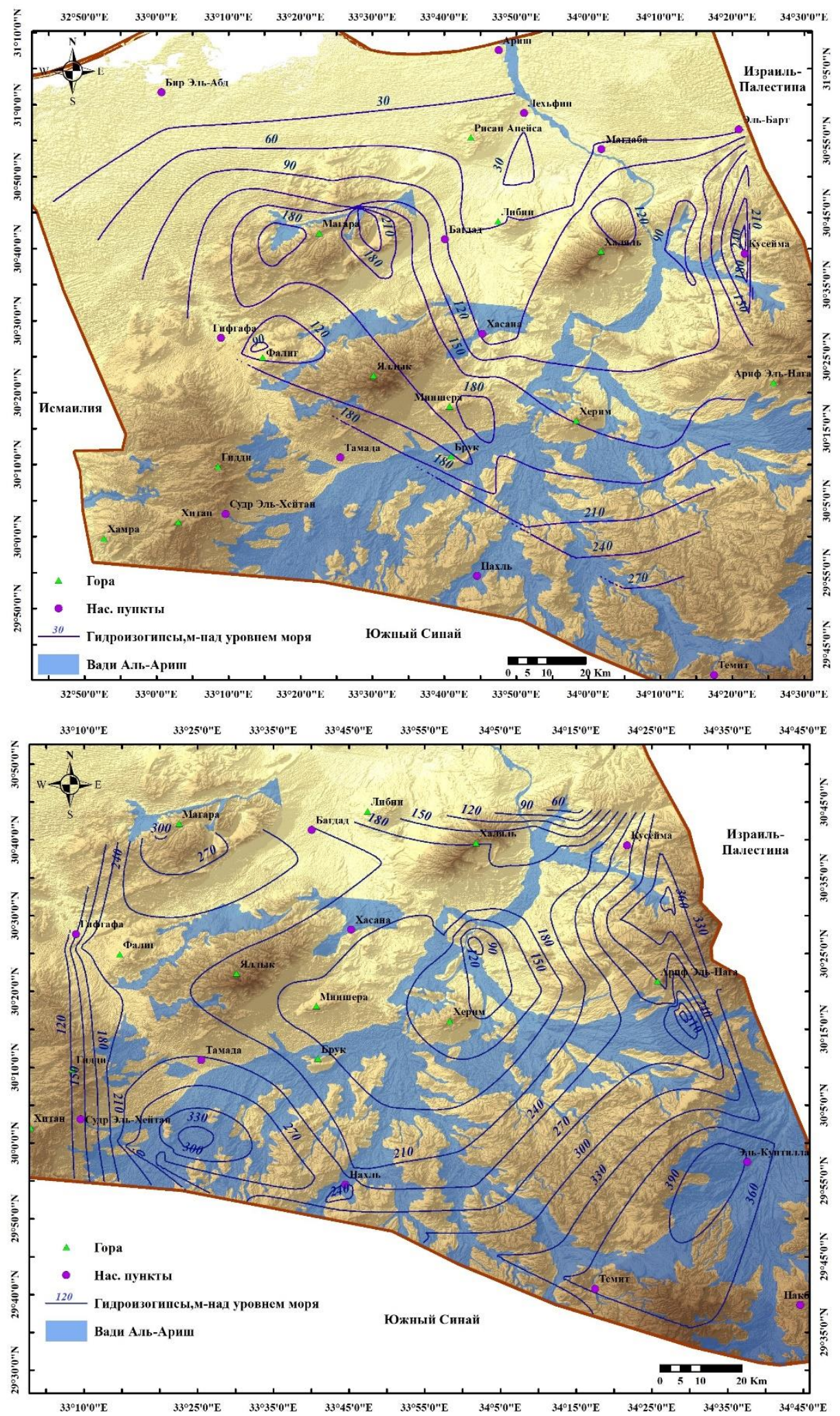

Рис. 4. Карта гидроизопьез дочетвертичных водоносных горизонтов: $a$ - верхнемеловых, $b$ - нижневерхнемеловых.

[Fig. 4. Map of hydroisopieses of pre-Quaternary aquifers: (a) - Upper Cretaceous, $(b)$ - Lower Upper Cretaceous. Translation symbols from the тар: Гора - Mountain, Нас. пункты - Cities and localities, Израиль-Палестина-Israel and Palestine, Гидроизогипсь- hydroisohypsum, mabove sea level, Вади Аль-Apии - Wadi El-Arish, Южный Синай-Hac. пункты - Cities and localities, Романа -Ruттапаһ, Бир Эль-Aбд-Biral-Abd, Paфax-Rafah, Арим - Arish, Шейх Зувайнд - Sheikh Zuweid, Эль-Барт - El-Bart, Магдаба - Magdaba, Mazapa - Magara, Лeхьфин - Lekhfin, Гифгафa - Gifgafa, Puсан Анейса - Risan Aneisa, Багдад - Baghdad, Либни - Libni, Фалиг - Falig, Ялльк-Yallyk, Тамада - Thaтаda, Гидди - Gidi, Хамра -Hатra, Хитам - Hitam, Хасана - Hasana, Миниера - Minshera, Халяль - Halyal, Kусеймa - Quseima, Cyдр Эль-Хейтан - Sudr El-Heitan, Apиф Эль-Haza - Arif El-Naga, ЭльКунтилла-El Kuntilla, Гемит-Gemit, Набк-Nabq, Нахль-Nakhl, Брук-Bruq.] 


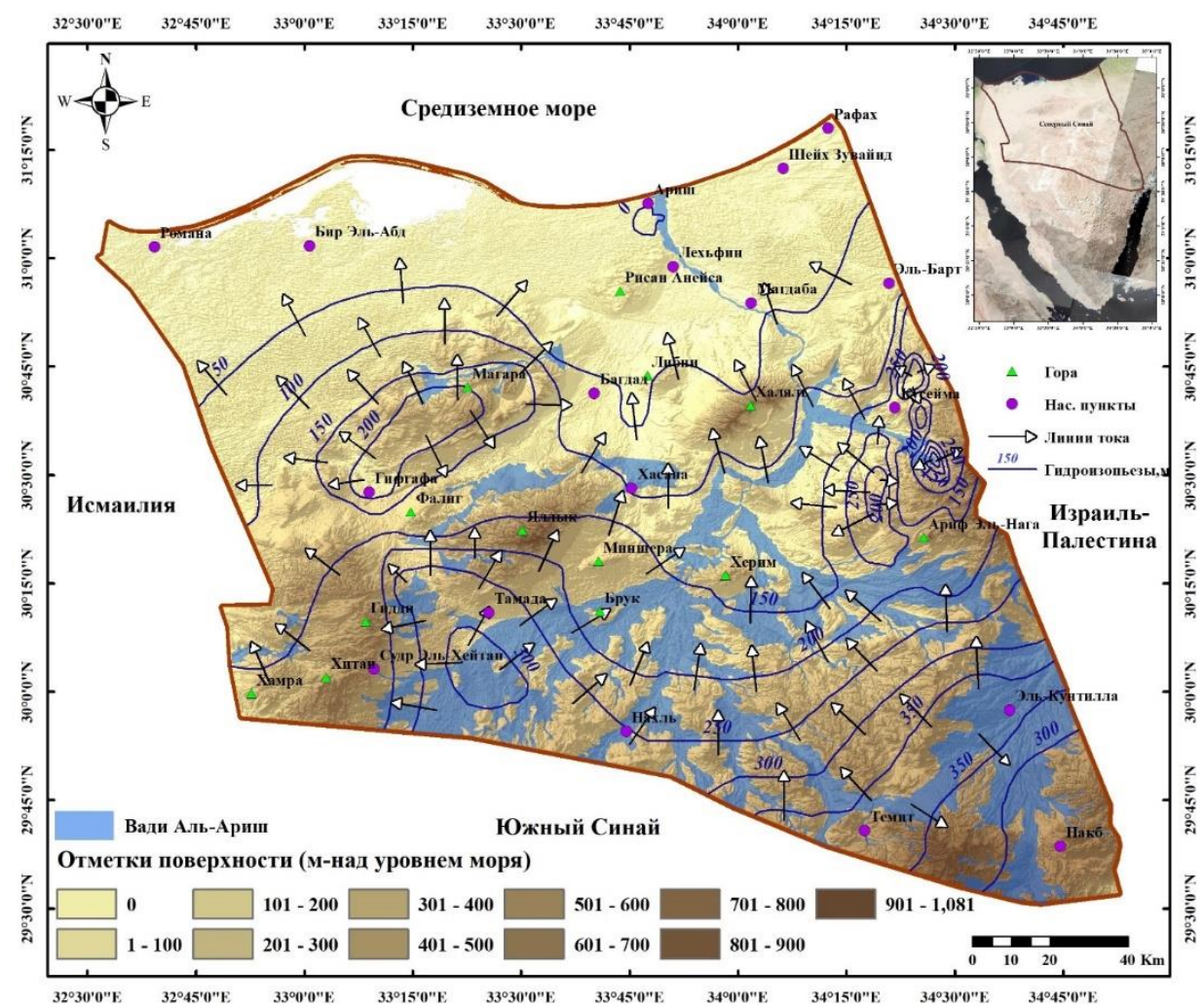

Рис. 5. Обобщенная структура фильтрационного потока подземных вод Северного Синая.

[Fig. 5. Generalised structure of the filtration flow of groundwater in the North Sinai. Translation symbols from the тар: Линии токаFlow lines, Отметки поверхности - Ground level. Гора - Mountain, Линии тока - Flood lines, гидроизопьезы - hydroisopies, Hac. пункты - Cities and localities, Романа - Ruтmanah, Бир Эль-Aбд - Bir al-Abd, Paфax - Rafah, Apиш - Arish, Шейх Зувайнд - Sheikh Zuweid, Эль-Барт - El-Bart, Магдаба - Magdaba, Mazapa - Magara, Лехьфин - Lekhfin, Гифгафа - Gifgafa, Pисан Анейса - Risan Aneisa, Багдад - Baghdad, Либни - Libni, Фалиг - Falig, Ялльк-Yallyk, Taмада - Thamada, Гидди - Gidi, Хамра -Hатra, Хитам Hitam, Хасана - Hasana, Миншера - Minshera, Халяль - Halyal, Кусейма - Quseima, Судр Эль-Хейтан - Sudr El-Heitan, Apиф ЭльHaza - Arif El-Naga, Эль-Кунтилла - El Kuntilla, Гемит - Gemit, Набк - Nabq, Hахль - Nakhl, Брук - Bruq.]

\section{Заключение}

Анализ карт гидроизогипс и гидроизопьез показал основное направление фильтрационного потока подземных вод в различных водоносных горизонтах с юга на север к - Средиземному морю. Локальными дренами, имеющими значение для четвертичных водоносных горизонтов, являются вади. Общая структура фильтрационного потока характеризуется как выше обозначенными горизонтальными движениями, так и вертикальными перетоками между четвертичными и дочетвертичными водоносными комплексами. Обобщенная карта структуры фильтрационного потока подземных вод станет основой развития водохозяйственного комплекса в пределах Северного Синая.

Конфликт интересов: Авторы декларируют отсутствие явных и потенциальных конфликтов интересов, связанных с публикацией настоящей статьи.

\section{ЛИТЕРАТУРА}

1. Косинова И. И., Косинов А. Е. Особенности формирования эколого-гидрохимических особенностей поверхностных вод реки Иордан, Израиль // Международный научный вестник (Вестник Объединения православных ученых). 2019. № 2 (22). C. $53-56$
2. Issar A. S., Bruins H. J. Special Climatological Conditions in the Deserts of Sinai and the Negev during the Latest Pleistocene // Elsevier Science Journal of Palaeogeography, Palaeoclimatology, Palaeoecology. 1983. Vol. 43. P. 63-72.

3. Rosenthal E., Adar E., Issar A., Batelaan O. Definition of groundwater flow patterns by environmental tracers in the multiple aquifer system of southern Arava Valley, Israel // Journal of Hydrogeology. 1990. Vol. 117. P. 339-368.

4. Issar A., Bein A., On the Ancient Water of the Upper Nubian Sandstone Aquifer in Central Sinai and Southern Israel // Journal of Hydrology. 1972. Vol. 17. P. 353-374.

5. Effat H. A., Hegazy M. N. Mapping potential landfill sites for North Sinai cities using spatial multicriteria evaluation // The Egyptian Journal of Remote Sensing and Space Science. 2012. Vol. 15. Issue 2. P. 125-133.

6. Sultan A. S. The Use of Geophysical and Remote Sensing Data Analysis in the Groundwater Assessment of El Qaa Plain, South Sinai, Egypt. $5^{\text {th }}$ International Conference on Water Resources and Arid Environments (ICWRAE 5), Riyadh, Saudi Arabia, 2013. P. 292-305.

7. Ghaffar M .K., Abdellatif, A. D., Azzam M. A., Riad M. H. Watershed Characteristic and Potentiality of Wadi El-Arish, Sinai, Egypt // International Journal of Advanced Remote Sensing and GIS. 2015. Vol. 4. Issue 1. P. 1070-1091.

8. Mohamed L., Sultan M., Ahmed M., Zaki A., Sauck W. Structural Controls on Groundwater Flow in Basement Terrains: Geophysical, Remote Sensing, and Field Investigations in Sinai // 
Springer journal of Surv. and Geophys. 2015. Vol. 36. P. 717 742. DOI: https://doi.org/10.1007/s10712-015-9331-5.

9. Omran E. A stochastic simulation model to early predict susceptible areas to water table level fluctuations in North Sinai, Egypt // The Egyptian Journal of Remote Sensing and Space Science. 2016. Vol. 19. Issue 2. P. 235-257.

10. El-Rayes A. E., Arnous M.O., Aziz A. M. Morphotectonic controls of groundwater flow regime and relating environmental impacts in Northwest Sinai, Egypt // Arab Journal of Geosciences. 2017. Vol. 10. P. 401-420.

11. Japan International Cooperation Agency (JICA), (1992). Main report: North Sinai Groundwater Resources Study in the Arab Republic of Egypt [Электронный pecypc]. URL: https://www.jica.go.jp/english/ (дата обращения: 23.05.2021).

12. Abd El Aal G.A. Thesis: Hydrogeology and Land Use Classification of North Sinai Peninsula with the Environmental Impact of Groundwater on Exploitation and Pollution, Egypt. 1998. 13. Министерство водных ресурсов и ирригации. Атлас наводнений долин Синайского полуострова. Нил Корниш Имбаба. Арабская Республика Египет. 2017 [Электронный pecypc]. C. 188. URL: www.mwri.org.eg (дата обращения: 06.06.2021) (на арабском языке)

14. Министерство водных ресурсов и ирригации. Атлас изменения климата Синайского полуострова. Нил Корниш Имбаба. Арабская Республика Египет [Электронный ресурс]. 2016. C. 200. URL: www.mwri.org.eg (на арабском языке) (дата обращения: 06.06.2021)
15. Государственное министерство по вопросам окружающей среды - Агентство по вопросам окружающей среды, Северный Синай - Управление по вопросам окружающей среды. Экологическая характеристика Северный Синай. Северный Синай. Арабская Республика Египет. 2007. С. 315. (на арабском языке).

16. База данных Главного управления Египта по минеральным ресурсам. Аль-Вайли - Каир. Арабская Республика Египет. 2018.

17. База данных Института исследований водных ресурсов Национальный центр водных исследований - Министерство водных ресурсов и ирригации - Арабская Республика Египет [Электронный pecypc]. URL: www.mwri.org.eg (дата обращения: 06.06.2021)

18. База данных Института исследования изменения климата - Национальный центр водных исследований - Министерство водных ресурсов и ирригации - Арабская Республика Египет [Электронный ресурc]. URL: www.mwri.org.eg (дата обращения: 06.06.2021)

19. Косинова И. И, Кустова Н. Р. Теория и методология геоэкологических рисков // Вестник Воронежского государственного университета. Серия: Геология. 2008. № 2. С. 189-197.

20. Мохамед Я. Ш., Виноград Н. А., Потапов А. А. Структура фильтрационных потоков подземных вод на севере Синайского полуострова. Геология, геоэкология, эволюционная география: Коллективная монография, Том XIX. Под ред. Е.М. Нестерова, В.А. Снытко. СПб., 2020. С. 259-262
Мохамед Яссер Эл Сайед Шаабан - ассистент, Загазигский университет, г. Загазиг, Арабская Республика Египет. Еmail: yasershaban122.a@gmail.com; ORCID http://orcid.org/0000-0002-3114-132X

Бударина Виктория Александровна - к. юр. н., доцент, Воронежский государственный университет, Воронеж, Российская Федерация; E-mail: budarinav@ yandex.ru, ORCID http://orcid.org/0000-0001-8091-0730

Косинова Ирина Ивановна - д. г.-м. н., профессор, Воронежский государственный университет, Воронеж, Российская Федерация; E-mail: kosinova777@ @andex.ru; ORCID http://orcid.org/0000-0002-5439-5197

Виноград Наталия Анатольевна - к. г.-м. н., доцент, СанктПетербургский государственный университет, Санкт-Петербург, Российская Федерация; E-mail: nv.70@ hotmail.com; ORCID http://orcid.org/0000-0002-6730-5453

Потапов Александр Анатольевич - к. г.-м. н., зав. сектором гидрогеологии, Горный институт Уральского отделения Российской академии наук, филиал Пермского федерального исследовательского центра УрО РАН, Пермь, Российская Федерация; E-mail: potapov @ dhspb.ru; ORCID http://orcid.org/0000-0003-4255-766X

Авторы прочитали и одобрили окончательный вариант рукописи.
Mohamed, Yasser El Sayed Shaaban - Assistant Lecturer, Zagazig University, Zagazig, Arab Republic of Egypt. E-mail: yasershaban122.a@gmail.com; ORCID http://orcid.org/0000-00023114-132X

Victoria A. Budarina - Ph.D in law, associate professor, Voronezh State University, Voronezh, Russian Federation; E-mail: budarinav@yandex.ru; ORCID http://orcid.org/0000-00018091-0730

Irina I. Kosinova - Dr. habil. in Geol.-Min., Professor, Voronezh State University, Voronezh, Russian Federation; Email:kosinova777@yandex.ru; ORCID http://orcid.org/00000002-5439-5197

Natalia A. Vinograd - PhD in Geol.-Min., Associate Professor, Saint Petersburg State University, Saint Petersburg, Russian Federation; E-mail: nv.70@hotmail.com; ORCID http://orcid.org/0000-0002-6730-5453

Alexander A. Potapov - PhD in Geol.-Min., Head of the sector of Hydrogeology. Mining Institute of the Ural branch of the Russian Academy of Sciences, branch of the Perm Federal research center Uro RAS, Perm, Russian Federation; E-mail: potapov@dhspb.ru; ORCID http://orcid.org/0000-0003-4255-766X

All authors have read and approved the final manuscript. 
UDC 556.3

ISSN 1609-0691

DOI: https://doi.org/10.17308/geology.2021.4/3792

Received: 18.08 .2021

Accepted: 01.12.2021

Published online: 17.12.2021

\title{
Natural and man-made factors in the formation of the groundwater filtration flows of the North Sinai
}

\author{
(c)2021 Y. Sh. Mohamed 1 , V. A. Budarina ${ }^{2 凶}$, I. I. Kosinova², N. A. Vinograd ${ }^{3}$, A. A. Potapov ${ }^{4}$ \\ ${ }^{I}$ Zagazig University, ul. El Modir, 44519 Zagazig, Sharkia, Arab Republic of Egypt \\ ${ }^{2}$ Voronezh State University, 1 Universitetskaya pl., Voronezh 394018, Russian Federation \\ ${ }^{3}$ St. Petersburg State University, 7/9 Universitetskaya naberezhnaya, \\ Saint-Petersburg 199034, Russian Federation \\ ${ }^{4}$ Mining Institute of the Ural Branch of the Russian Academy of Sciences, branch of Perm Federal \\ Research Centre of UB RAS, 78a Sibirskaya ul., Perm 614007, Perm region, Russian Federation
}

\begin{abstract}
Introduction: The northern part of the Sinai Peninsula is situated in an area of arid climate, and the region is characterised by an acute shortage of available water of satisfactory quality. Hydrogeological wells are almost the only source of fresh water. Further development of the region focused on the expansion of the mining activities requires a considerable increase of the need in water. Therefore, the goal of this work was to study natural and man-made factors in the formation of groundwater filtration flows that are used and can be used in the future for utility and drinking water in the northern part of the Sinai Peninsula.

Methodology: The methodology of the conducted studies included the creation of a database of level regimes of Quaternary and Pre-Quaternary aquifers of the region with the observations from 151 wells. 45 aquifers characterised the hydrogeological situation for Quaternary deposits in three areas: the valley Wadi El-Arish, and in the regions of Rafah and Sheikh Zuweid. Pre-Quaternary aquifers were assessed by the sampling of 60 wells. Using SPSS, we conducted a statistical analysis to assess the measured levels of water in hydrogeological wells and, based on them and using geographic information system (GIS), we constructed hydroisogypsum and hydroisopyeses maps for each aquifer and then we prepared a generalised hydrodynamic grid of the flow to track the movement of groundwater in the North Sinai.

Results and discussion: The distribution of highly powerful aquifers in Quaternary deposits is limited only by the coastal plain stretching along the Mediterranean Sea. The following principal patterns of the formation of groundwater filtration flows of the North Sinai were determined: a) the general groundwater flow moves in a sub-horizontal direction, mainly from the south to the north, in the direction of the general flow into the Mediterranean Sea, and also partially in the western and eastern directions towards the Gulf of Suez and the Gulf of Aqaba; b) on average, the hydraulic slope of the main filtration Quaternary groundwater flow from south to north is about 0.002 ; c) the values of statical levels of groundwater in Quaternary deposits within the coastal plain are within the range from +8.10 to $-8.40 \mathrm{~m}$, the negative values are typical for the sections of the operation of the production wells; d) Pre-Quaternary aquifers are deposited within the range of depths from 3.1 to $420 \mathrm{~m}$. The hydraulic slopes in aquifers of Quaternary groundwater deposits are recorded in sandstone $(330-410 \mathrm{~m}$ abs.) and are 0.003 ; e) there is a general tendency towards the increased mineralisation as the absolute elevation of the groundwater level decreases.
\end{abstract}

\footnotetext{
$凶$ Victoria A. Budarina, e-mail: budarinav@yandex.ru
} 
Conclusions: The identified natural and man-made factors in the formation of groundwater filtration flows of the Sinai Peninsula will allow optimising the existing water supply by making the use of the Quaternary aquifer in the central part of the studied area more effective and by scientific justification of the operation of chalk aquifers excluding the increased mineralisation of groundwater. The generalised structure map of the filtration flow can be used as a basis for the development of the water supply complex within the North Sinai. Keywords: groundwater flow, Quaternary and Pre-Quaternary aquifers, hydrodynamic grid, Sinai Peninsula.

Funding: The article was prepared with the support of the Russian Foundation for Basic Research, contract No. 20-55-00010 of 30.04.2020 and the Belarusian Republican Foundation for Basic Research, contract NoX20P-284 of 04.05.2020.

For citation: Mohamed Y. Sh., Budarina V.A., Kosinova I.I., Vinograd N. A., Potapov A. A. Natural and man-made factors in the formation of the groundwater filtration flows of the North Sinai. Vestnik Voronezhskogo gosudarstvennogo universiteta. Seriya: Geologiya - Proceedings of Voronezh State University. Series: Geology, 2021, no. 4, pp. 71-81. DOI: https://doi.org/10.17308/geology.2021.4/3792

Conflict of interests: The authors declare the absence of obvious and potential conflicts of interest related to the publication of this article.

\section{REFERENCES}

1. Kosinova I. I., Kosinov A. E. Osobennosti formirovaniya ekologo-gidrokhimicheskikh osobennostei poverkhnostnykh vod reki Iordan, Izrail' [Features of the formation of ecological and hydrochemical features of surface waters of the Jordan River, Israel]. Mezhdunarodnyi nauchnyi vestnik (Vestnik Ob"edineniya pravoslavnykh uchenykh) - International Scientific Bulletin (Bulletin of the Association of Orthodox Scientists), 2019, no. 2 (22), pp. 53-56. (In Russ.)

2. Issar A. S., Bruins H. J. Special Climatological Conditions in the Deserts of Sinai and the Negev during the Latest Pleistocene. Elsevier Science Journal of Palaeogeography, Palaeoclimatology, Palaeoecology, 1983, vol. 43, pp. 63-72.

3. Rosenthal E., Adar E., Issar A., Batelaan O. Definition of groundwater flow patterns by environmental tracers in the multiple aquifer system of southern Arava Valley, Israel. Journal of Hydrogeology, 1990, vol. 117, pp. 339-368.

4. Issar A., Bein A., On the Ancient Water of the Upper Nubian Sandstone Aquifer in Central Sinai and Southern Israel. Journal of Hydrology, 1972, vol. 17, pp. 353-374.

5. Effat H. A., Hegazy M. N. Mapping potential landfill sites for North Sinai cities using spatial multicriteria evaluation. The Egyptian Journal of Remote Sensing and Space Science, 2012, vol. 15, issue 2, pp. $125-133$.

6. Sultan A. S. The Use of Geophysical and Remote Sensing Data Analysis in the Groundwater Assessment of El Qaa Plain, South Sinai, Egypt. $5^{\text {th }}$ International Conference on Water Resources and Arid Environments (ICWRAE 5), Riyadh, Saudi Arabia, 2013, pp. 292-305.

7. Ghaffar M .K., Abdellatif, A. D., Azzam M. A., Riad M. H. Watershed Characteristic and Potentiality of Wadi El-Arish, Sinai, Egypt. International Journal of Advanced Remote Sensing and GIS, 2015, vol. 4, issue 1, pp. 1070-1091.

8. Mohamed L., Sultan M., Ahmed M., Zaki A., Sauck W. Structural Controls on Groundwater Flow in Basement Terrains: Geophysical, Remote Sensing, and Field Investigations in Sinai. Springer journal of Surv. and Geophys, 2015, vol. 36, pp. 717-742. DOI: https://doi.org/10.1007/s10712-015-9331-5.

9. Omran E. A stochastic simulation model to early predict susceptible areas to water table level fluctuations in North Sinai, Egypt. The Egyptian Journal of Remote Sensing and Space Science, 2016, vol. 19, issue 2, pp. 235-257.

10. El-Rayes A. E., Arnous M. O., Aziz A. M. Morphotectonic controls of groundwater flow regime and relating environmental impacts in Northwest Sinai, Egypt. Arab Journal of Geosciences, 2017, vol. 10, pp. 401-420.

11. Japan International Cooperation Agency (JICA), (1992). Main report: North Sinai Groundwater Resources Study in the Arab
Republic of Egypt. Available at: https://www.jica.go.jp/english/ (accessed 23 may 2021)

13. Abd El Aal G.A. Thesis: Hydrogeology and Land Use Classification of North Sinai Peninsula with the Environmental Impact of Groundwater on Exploitation and Pollution, Egypt. 1998.

14. Ministerstvo vodnykh resursov i irrigatsii. Atlas navodnenii dolin Sinaiskogo poluostrova. Nil Kornish - Imbaba. Arabskaya Respublika Egipet [Ministry of Water Resources and Irrigation, (2017). "Atlas of torrents of the valleys of the Sinai Peninsula". Nile Corniche - Imbaba. The Arab Republic of Egypt]. Available at: www.mwri.org.eg (In Arabic) (accessed 6 June 2021)

15. Gosudarstvennoe ministerstvo po voprosam okruzhayushchei sredy - Agentstvo po voprosam okruzhayushchei sredy, Severnyi Sinai - Upravlenie po voprosam okruzhayushchei sredy. Ekologicheskaya kharakteristika Severnyi Sinai. Severnyi Sinai. Arabskaya Respublika Egipet [Ministry of State for Environmental Affairs - Environmental Affairs Agency, North Sinai Governorate - Environmental Affairs Administration, Environmental characterization of North Sinai Governorate. North Sinai Governorate. The Arab Republic of Egypt]. 2007, 315 p. (In Arabic)

16. Baza dannykh Glavnogo upravleniya Egipta po mineral'nym resursam. Al'-Vaili - Kair. Arabskaya Respublika Egipet. [Database of the Egyptian General Authority for Mineral ResourcesEl Weili Cairo. The Arab Republic of Egypt], 2018.

17. Baza dannykh Instituta issledovanii vodnykh resursov - Natsional'nyi tsentr vodnykh issledovanii - Ministerstvo vodnykh resursov i irrigatsii - Arabskaya Respublika Egipet [Water Resources Research Institute database - National Water Research Center - Ministry of Water Resources and Irrigation. The Arab Republic of Egypt]. Available at: www.mwri.org.eg (In Arabic) (accessed 6 June 2021)

18. Baza dannykh Instituta issledovaniya izmeneniya klimata Natsional'nyi tsentr vodnykh issledovanii - Ministerstvo vodnykh resursov i irrigatsii - Arabskaya Respublika Egipet [Climate Change Research Institute database - National Water Research Center - Ministry of Water Resources and Irrigation. The Arab Republic of Egypt]. Available at: www.mwri.org.eg (In Arabic) (accessed 6 June 2021) 19. Kosinova I. I, Kustova N. R. Teoriya i metodologiya geoekologicheskikh riskov [Theory and methodology of geoecological risks]. Vestnik Voronezhskogo gosudarstvennogo universiteta. Seriya: Geologiva - Proceedings of Voronezh State University. Series: Geology, 2008, no. 2, pp. 189-197. (In Russ.)

20. Mohamed Ya., Vinograd N. A., Potapov A. A. Struktura fil'tratsionnykh potokov podzemnykh vod na severe Sinaiskogo poluostrova. Geologiya, geoekologiya, evolyutsionnaya geografiya: Kollektivnaya monografiya, Tom XIX. [Structure of the groundwater flow in the north of the Sinai peninsula In: Geology, Geoecology and Evolution geography: collective monograph, vol. XIX] E.M. Nesterov, V.A. Snytko (Eds). St.Petersburg, RGPU publ., 2020, pp. 259-262. (In Russ.) 